
ul. Czartoryskich 8, 24-100 Puławy, Poland

\title{
In memory of Professor Alina Kabata-Pendias (1929-2019)
}

\begin{abstract}
Professor Alina KabataPendias passed away on April $3^{\text {rd }} 2019$. She was a researcher at the Institute of Soil Science and Plant Cultivation (IUNG) in Puławy, and an expert, international authority in the field of trace element biogeochemistry.

Professor Alina KabataPendias was born on September $8^{\text {th }}, 1929$ in Baranowicze. In 1949, she completed the thesis: ,Physical and biological properties of soils" and received
\end{abstract} the degree of a farmer's en-

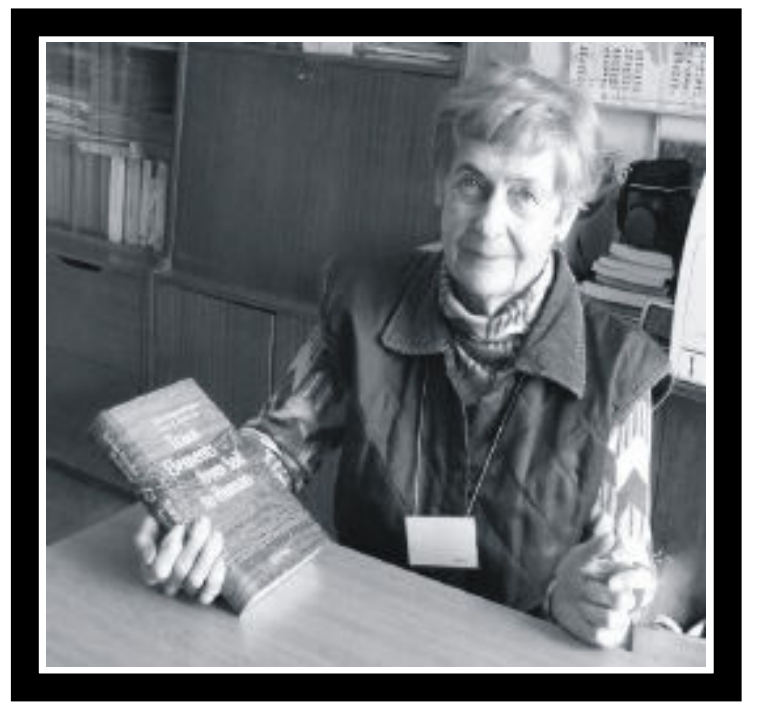

dies were innovative and set future directions in biogeochemistry. Her scientific interest focused on i) analysis of the relationship between the content of trace elements in soil solution and in plants; ii) assessment of the effect of soil properties on the content and forms of trace elements in soils; iii) evaluation of ,background value" of trace elements in soils; iv) the use of phytoindication methods for evaluation of the degree of soil contaminagineer from the Faculty of Agriculture at the Higher School of Rural Husbandary in Cieszyn. That year, she started working as a junior assistant at the Department of Soil Science of the State Research Institute of Rural Husbandry (PINGW) in Puławy and continuing her Master Degree. In 1950, she published the monograph "Occurrence of copper in the soils of the S'więtokrzyskie region" and graduated with a M.Sc. from the Maria Curie-Skłodowska University in Lublin. In 1957, the Scientific Council of IUNG nominated her $\mathrm{PhD}$ in agricultural sciences for her work on „CO, Cu and Ni content in some important soils and hay of grasslands from neighorhood of Noteć and Bug rivers. In 1966, she published the monograph "Geochemical-mineralogical studies of soils developed from granites and basalts of Lower Silesia" and was awarded the degree of habilitated doctor. In recognition of her accomplishments, she was nominated by the Council of the State of Poland as Professor Extraordinary (1974) and then Professor Ordinary (1984).

From 1949 to 2003, Professor Alina Kabata-Pendias was involved in activities of the Department of Soil Science at IUNG in Puławy. Many of her stu- tion with metals and v) the transport of metals in the human food chain. Professor Alina Kabata-Pendias was also employed (1960-1990) at the Department of Petrography and Mineralogy at the National Geological Institute (PIG) in Warsaw, where she worked on evaluation of the content and composition of trace elements in various rocks deposits.

During her early scientific career (1950-1956), she completed courses in analytical chemistry at the Technical University of Warsaw (1952-1953); Carlov University in Prague (1955) and at the Institute for Soils Research in Aberdeen (1956). She was also granted a Rockefeller Foundation fellowship and worked (1958-1959) in the U.S. Plant, Soil and Nutrition Laboratory in Ithaca, N.Y. where she participated in studies on the sorption properties of clay minerals towards trace elements and evaluated the degree of cobalt absorption by plants.

She published over 300 articles, symposium proceedings and book chapters. She is a well-known author and/or coauthor of 11 books printed in Polish, English and Russian. Together with her coworkers, she introduced the first quality criteria for Polish agricultural soils contaminated with trace 
elements she was the chairperson in the journal Zeszyty Naukowe PAN, seria Pierwiastki śladowe w środowisku - problemy ekologiczne i metodyczne and the member of editorial board in Environmental Geochemistry and Health as well as Advances in Trace Substances Research journals.

In 1961-1979 Profesor Alina Kabata- Pendias was the main investigator in three projects realized in cooperation with USDA Agricultural Research Service: Distribution of micro nutrients among soil minerals (1961-1966), The occurrence and behavior of trace elements in residual soils (1969-1975); The impact of copper mining and industrial activity of Lower Silesia on the chemical composition of plants (1975-1979). She was the coordinator, as well as the main investigator, of numerous national projects granted by the Ministry of Agriculture, Ministry of Environmental Protection and the State Committee for Scientific Research. She was the consultant and lecturer from FAO, UNEP, MAB, SCOPE, SETAC and IUPAC organizations. She was involved in education activities giving courses for post-graduate researchers. Seven young scientists have completed their Ph.D. thesis under her supervision. She served as reviewer of fifteen habilitation degree thesis and ten Professor's State Nominations.

Professor Alina Kabata-Pendias was a chairperson of two and the member of several scientific committees of the Polish Academy of Science. She also joined several scientific associations e.g. the Soil Science Society of Poland, Mineralogical Society of Poland, Geological Society of Poland, International Union of Soil Sciences, Society for Environmental Geochemistry and Health as well as International Association for Study of Clay.

Professor A. Kabata-Pendias received several professional national and international awards among them Knight's Cross of the Order of Polonia Restituta (1990) as a team member $1^{\text {st }}$ Degree Price from the Minister of Agriculture (1995), Philippe Duchaufour Medal awarded by the European Geosciences Union (2007) and the Medal of $75^{\text {th }}$ Anniversary of Soil Science Society of Poland (2012). During the Second World War she was the active member of the underground Home Army organization and in recognition of her merits she was bestowed with the most honored Cross of Home Army (1994).

Professor Alina Kabata-Pendias was an outstanding person who had a huge impact on today's global perception of soil pollution. She was faithful to the words ,As long as I am active, I will try to enrich the understanding of human dependence on the geochemical properties of the surrounding environment" written as a scientific testament in 1985 . We will remember Professor Alina Kabata-Pendias as a great professional, a hardworking researcher and also an open, friendly and kind-hearted person.

The most important scientific publications, books and monographs by Professor Alina Kabata-Pendias are listed below.

\section{Books:}

1. Kabata-Pendias A., Pendias H., 1979. Pierwiastki śladowe w środowisku biologicznym. Wyd. Geol. Warszawa, ss. 300.

2. Kabata-Pendias A., Pendias H., 1984. Trace elements in soils and plants. CRS Press, Boca Raton, Fl, ss. 315.

3. Kabata-Pendias A., Pendias H., 1989. Mikroelementy w glebach i roślinach. Moskwa, „Mir”, ss. 439. (RUS)

4. Kabata-Pendias A., Pendias H., 1992. Trace elements in soils and plants. $2^{\text {nd }}$ edition, CRS Press, Boca Raton, Fl., pp. 365.

5. Kabata-Pendias A., Pendias H., 1993. Biogeochemia pierwiastków śladowych. PWN, Warszawa, ss. 364.

6. Kabata-Pendias A., Pendias H., 1999. Biogeochemia pierwiastków śladowych. 2 wydanie, PWN, Warszawa, ss. 400.

7. Kabata-Pendias A., Pendias H., 2001. Trace elements in soils and plants. 3rd edition, CRS Press, Boca Raton, Fl., pp. 423.

8. Kabata-Pendias A., Mukherjee A., 2007. Trace elements from soils to human. Springer-Verlag, Berlin, 2007, pp. 550.

9. Kabata-Pendias A. 2011. Trace elements from soils to plants. 4th edition, CRS Press, Francis\&Taylor Group, Boca Raton Fl., pp. 520.

10. Kabata-Pendias A., Szteke B., 2012. Pierwiastki śladowe w geo- i biosferze. Wyd. IUNG, Puławy, ss. 275.

11. Kabata-Pendias A., Szteke B., 2015. Trace elements in abiotic and biotic environments. CRS Press, Francis\&Taylor Group, Boca Raton Fl., pp. 440.

\section{Selected publications and book chapters:}

1. Kabata A., 1954. O zawartości kobaltu w niektórych glebach obszaru Świętokrzyskiego. Roczniki Gleboznawcze - Soil Science Annual 3: 323-332.

2. Kabata A., 1961. Przegląd fotometrycznych metod oznaczania mikroelementów w roślinach i glebach. Pamiętnik Puławski (3): 81-91.

3. Kabata A., Beeson K.C., 1961. Cobalt uptake by plants from cobalt impregnated soil minerals. Soil Sci. Soc. Am. Proc. (25): 125-128.

4. Kabata-Pendias A., 1965. Badania geochemicznomineralogiczne gleb wytworzonych z granitów i bazaltów Dolnego Śląska. Roczn. Nauk Roln. (90A-1): 1-60.

5. Kabata-Pendias A., 1965. Niektóre pierwiastki śladowe w rędzinach województwa kieleckiego. Con- 
tent of certain trace elements in rendzinas of the Kielce region, Roczniki Gleboznawcze - Soil Science Annual 15 (dod.): 251-260.

6. Kabata-Pendias A., 1966. Badania geochemicznomineralogiczne dwóch gleb wytworzonych $\mathrm{z}$ piaskowców. Roczn. Nauk Roln. (92-A-2): 185-213.

7. Kabata-Pendias A., 1968. The sorption of trace elements by soil-forming minerals. Roczniki Gleboznawcze - Soil Science Annual 19 (dod.): 55-72.

8. Kabata-Pendias A., Piotrowska M., 1972. Metale ciężkie w preparatach i nawozach stosowanych w rolnictwie. Post. Nauk Roln. (2): 13-29.

9. Kabata-Pendias A., Tarłowski P., 1970. Wydzielanie roztworów glebowych metodą wirowania. Roczniki Gleboznawcze - Soil Science Annual 21: 457-461.

10. Kabata-Pendias A., 1972. Chemiczny skład roztworów glebowych. Roczniki Gleboznawcze - Soil Science Annual 23(1): 3-14.

11. Kabata-Pendias A., Pendias H., 1973. Szkodliwość nadmiernego stężenia metali ciężkich w środowisku biologicznym. Z. Probl. Post. Nauk Rol. (145): 63-78.

12. Kabata-Pendias A., 1977. Influence of lead on chemical composition of grass (Bromus unioloides). Rocz. Nauk Roln. 102 (Ser. A): 29-38 (PL).

13. Kabata-Pendias A., 1977. Metale ciężkie w roślinach rosnących na odpadach flotacyjnych przemysłu miedziowego. Roczniki Gleboznawcze - Soil Science Annual 28(2): 141-154.

14. Kabata-Pendias A., 1978. The impact of copper mining and industrial activity of Lower Silesia on the chemical composition of plants. IUNG Puławy, pp. 172.

15. Kabata-Pendias A., Gondek B., 1978. Bioavailability of heavy metals in the vicinity of a copper smelter. Trace Subst. Envir. Health 12: 523-531.

16. Kabata-Pendias A., 1979. Effects of lime and peat on heavy metal uptake by plants from soils contaminated by an emission of a copper smelter. Roczniki Gleboznawcze - Soil Science Annual 30(3): 123-133.

17. Kabata-Pendias A., Bolibrzuch E., 1979. Pierwiastki śladowe w wodach dorzecza Bystrej (Wyżyna Lubelska). Roczniki Gleboznawcze - Soil Science Annual 30(1): 107-123.

18. Kabata-Pendias A., 1979. Geochemia pierwiastków śladowych w glebach. Przegląd Geologiczny 27(10): 543-545.

19. Kabata-Pendias A., Piotrowska M., Fabe A., 1980. Stan i kierunki badań krajowych w zakresie skażenia gleb i roślin pierwiastkami śladowymi. [W:] Materiałach Konferencji ,Wpływ zanieczyszczenia pierwiastkami śladowymi i siarką na przyrodnicze warunki rolnictwa" Cz. I: 13-34.

20. Kabata-Pendias A., 1981. Heavy metal concentrations in arable soils of Poland. Pamiętnik Puławski 74: 101-111 (PL).
21. Kabata-Pendias A., Bolibrzuch E., Tarłowski P., 1981. Impact of a copper smelter on agricultural environments. Part I. Contamination of soils. Roczniki Gleboznawcze - Soil Science Annual 3: 207-214.

22. Kabata-Pendias A., Tarłowski P., 1981. Impact of copper smelter on agricultural environments. Part II. Contamination of herbage. Roczniki Gleboznawcze - Soil Science Annual 32(3): 215-221.

23. Kabata-Pendias A., Bolibrzuch E., 1981. Impact of copper of cultivated plants. Part III. Contamination of cultivated plant. Roczniki Gleboznawcze - Soil Science Annual 32(3): 223-228.

24. Kabata-Pendias A., Piotrowska M., 1983. Primary estimation of excessive levels of trace elements in soils and plants. [In:] Proceedings of International Superelements Symposium - Lithium. Jena: 369-375.

25. Kabata-Pendias A., Tarłowski P., Dudka S., 1985. Opad pierwiastków śladowych z atmosfery na powierzchnię gleby. Roczniki Gleboznawcze - Soil Science Annual 36(1): 137-139.

26. Kabata-Pendias A., Pondel H., 1985. Zagrożenia gleb użytków rolnych w Polsce. Roczniki Gleboznawcze - Soil Science Annual 36(1): 59-77.

27. Kabata-Pendias A., Wiącek K., 1985. Excessive uptake of heavy metals by plants from contaminated soils. Roczniki Gleboznawcze - Soil Science Annual 36(4): 33-42.

28. Kabata-Pendias A. \& Dudka S., 1991. Trace metal contents of Taraxacum officinale (dandelion) as a convenient environmental indicator. Environmental Geochemistry and Health (13): 108-113.

29. Kabata-Pendias A., Motowicka-Terelak T., Piotrowska M., Terelak H., Witek T., 1993. Ocena stopnia zanieczyszczenia gleb metalami ciężkimi i siarką. Ramowe wytyczne dla rolnictwa. Wyd. IUNG Puławy P(53): ss. 23.

30. Kabata-Pendias A., 1995. Agricultural Problems Related to Excessive Trace Metal Contents of Soils. [In:] Förstner U., Salomons W., Mader P. (eds) Heavy Metals. Environmental Science. Springer, Berlin, Heidelberg: pp. 3-18.

31. Kabata-Pendias A., Piotrowska M., MotowickaTerelak T., Maliszewska-Kordybach B., Filipiak K., Krakowiak A., Pietruch C., 1995 Podstawy oceny chemicznego zanieczyszczenia gleb. Metale ciężkie, siarka i WWA. Biblioteka Monitoringu Środowiska Warszawa.

32. Piotrowska M., Kabata-Pendias A., 1997. Impact of soils amended with $\mathrm{Zn}$ and $\mathrm{Pb}$ smelter dust on $\mathrm{Cd}$ concentrations in potatoes. Journal of Geochemical Exploration (58): 319-322.

33. Kabata-Pendias A., 1999. Behavioral properties of trace metals in soils. Applied Geochemistry 8 (supl. 2): 3-9.

34. Kabata-Pendias A., 2004. Soil-plant transfer of trace elements-an environmental issue. Geoderma 111 (24): 143-149. 


\section{Wspomnienie \\ Prof. dr hab. Alina Kabata-Pendias (1929-2019)}

W dniu 3 kwietnia 2019 roku zmarła prof. dr hab. Alina Kabata-Pendias długoletni pracownik naukowy Instytutu Uprawy Nawożenia i Gleboznawstwa (IUNG) w Puławach, ekspert i międzynarodowy autorytet $\mathrm{z}$ zakresu biogeochemii pierwiastków śladowych.

Prof. dr hab. Alina Kabata-Pendias urodziła się 8 września 1929 roku w Baranowiczach (obecnie teren Białorusi). W 1949 roku ukończyła studia I stopnia na Wydziale Rolnym Wyższej Szkoły Gospodarstwa Wiejskiego w Cieszynie i po przedłożeniu pracy ,Fizyczne i biologiczne właściwości gleb” uzyskała stopień inżyniera rolnika. W tym samym roku podjęła pracę na stanowisku młodszego asystenta w Zakładzie Gleboznawstwa Państwowego Instytutu Naukowego Gospodarstwa Wiejskiego (PINGW) w Puławach oraz rozpoczęła studia magisterskie na Wydziale Rolnym Uniwersytetu Marii Curie-Skłodowskiej w Lublinie. W 1950 roku uzyskała stopień magistra nauk rolniczych za opracowanie nt. ,,Występowanie miedzi w glebach rejonu świętokrzyskiego", a w 1957 roku Rada Naukowa IUNG z siedzibą w Warszawie nadała Jej stopień naukowy doktora nauk rolniczych za pracę nt. ,Zawartość Co, Cu i Ni $w$ wazniejszych glebach oraz sianie nadnoteckich i nadbużańskich terenów takowych". W 1966 roku otrzymała stopień naukowy doktora habilitowanego nadany Jej przez Wyższą Szkołę Rolniczą w Lublinie po przedłożeniu opracowania p.t. "Badania geochemiczno-mineralogiczne gleb wytworzonych z granitów i bazaltów Dolnego Ślaska”. W 1974 roku otrzymała od Rady Państwa tytuł naukowy profesora nadzwyczajnego, a w 1984 roku tytuł naukowego profesora zwyczajnego.

Od 1949 do 2003 roku prof. dr hab. Alina KabataPendias była związana z Zakładem Gleboznawstwa IUNG w Puławach. Wiele badań naukowych realizowanych w tym okresie przez prof. dr hab. Alinę Kabatę-Pendias miało charakter nowatorski i pionierski wyznaczając przyszłe kierunki prac z zakresu biogeochemii. Główne zagadnienia badawcze realizowane przez Panią Profesor w IUNG w Puławach dotyczyły: analiz zależności pomiędzy zawartością pierwiastków śladowych w roztworze glebowym i w roślinach; oceny wpływu właściwości gleb na zawartość i formy pierwiastków śladowych; oceny „tła naturalnego" pierwiastków śladowych w glebach; wykorzystania metod fitoindykacji w celu analizy stopnia zanieczyszczenia gleb metalami oraz transportu metali w łańcuchu żywieniowym człowieka.
W 1959 roku z inicjatywy i przy udziale Pani Profesor, w Zakładzie Gleboznawstwa IUNG w Puławach powstało Laboratorium Mikroelementów, którym kierowała do 1991 roku. W latach 1960-1990, prof. dr hab. Alina Kabata-Pendias była również zatrudniona w Zakładzie Petrografii i Mineralogii, Państwowego Instytutu Geologicznego (PIG) w Warszawie i prowadziła badania nad zawartościa pierwiastków śladowych w zwietrzelinach różnych rodzajów skał.

Na początku swojej kariery naukowej (lata 19501956) prof. dr hab. Alina Kabata-Pendias odbyła liczne staże naukowe m.in. w zakresie: analizy spektrofotometrycznej pierwiastków śladowych (Politechnika Warszawska, 1952), polarograficznych oznaczeń metali ciężkich (Instytut Polarograficzny w Pradze, 1955), metod analizy spektralnej pierwiastków śladowych w glebach i roślinach (the Macaulay Institute for Soil Research w Aberdeen, 1956). W okresie 1958-1959 była stypendystką Fundacji Rokefellera i pracowała w U.S. Plant, Soil and Nutrition Laboratory, Ithaca (N.Y.), gdzie uczestniczyła w badaniach ukierunkowanych na rozpoznanie sorpcyjnych właściwości minerałów ilastych w stosunku do pierwiastków śladowych oraz stopnia przyswajalności kobaltu przez rośliny.

Wiedza teoretyczna oraz praktyka, która prof. dr hab. Alina Kabata-Pendias zdobyła za granicą spowodowały, że w latach 1961-1979 była głównym wykonawcą w trzech projektach realizowanych przy współpracy z USDA Agricultural Research Service: Distribution of micronutrients among soil minerals (1961-1966), The occurence and behaviour of trace elements in residual soils (1969-1975); The impact of copper mining and industrial activity of Lower Silesia on the chemical composition of plants (19751979). Kierowała i uczestniczyła w licznych projektach zleconych przez ówczesne Ministerstwo Rolnictwa i Gospodarki Żywnościowej oraz Ministerstwo Ochrony Srodowiska, a także finansowanych przez Komitet Badań Naukowych.

Pani Profesor prowadziła szeroką działalność ekspercką. Była konsultantem i wykładowcą z ramienia FAO, UNEP, MAB, SCOPE, SETAC i IUPAC koncentrując się na problematyce zanieczyszczenia środowiska pierwiastkami śladowymi oraz ich wpływem na zdrowie człowieka. Prowadziła liczne wykłady i była zapraszana do wygłoszenia referatów plenarnych na międzynarodowych konferencjach naukowych. Przekazywała swoją wiedzę młodym pracownikom nauki. Była promotorem siedmiu oraz recenzentem 
czternastu prac doktorskich. Wykonała piętnaście ocen dorobku naukowego pracowników ubiegających się o nadanie stopnia naukowego doktora habilitowanego oraz recenzowała dziesięć wniosków o nadanie tytułu naukowego profesora.

Dorobek publikacyjny prof. dr hab. Aliny Kabaty-Pendias obejmuje ponad 300 prac metodycznych i naukowych, głównie o zasięgu międzynarodowym. Warto wspomnieć, że Pani Profesor w swoich publikacjach używała określenia „pierwiastki śladowe” wypełniając obietnice, którą złożyła w latach 80 . ubiegłego wieku. Prof. dr hab. Alina Kabata-Pendias była znaną i cenioną autorką lub współautorką książek na temat pierwiastków śladowych i ich zawartości w różnych elementach środowiska przyrodniczego. Książki te zostały wydane w języku polskim, angielskim i rosyjskim. Wraz z zespołem opracowała pierwszy w naszym kraju system oceny stopnia zanieczyszczenia pierwiastkami śladowymi gleb użytkowanych rolniczo, który został opublikowany w pracy pt. „,Ocena stopnia zanieczyszczenia gleb metalami ciężkimi i siarkq. Ramowe wytyczne dla rolnictwa" (1993). Do 2002 roku były to jedyne kryteria stosowane w naszym kraju do identyfikacji terenów zanieczyszczonych.

Pani Profesor była redaktorem Zeszytów Naukowych PAN, seria Pierwiastki śladowe w środowisku - problemy ekologiczne i metodyczne oraz członkiem komitetów wydawniczych czasopism: Environmental Geochemistry and Health i Advances in Trace Substances Research. Była też członkiem komitetów naukowych i organizacyjnych wielu konferencji międzynarodowych i krajowych, w tym pomysłodawca i głównym organizatorem cyklu konferencji nt. ,, Pierwiastki śladowe w środowisku przyrodniczym".

Prof. dr hab. Alina Kabata-Pendias uczestniczyła przez ponad 30 lat w pracach różnych Komitetów Polskiej Akademii Nauk. W uznaniu Jej wiedzy teoretycznej i praktycznej została powołana na przewodniczącą Komisji Analizy dla Potrzeb Rolnictwa Polskiej Akademii Nauk (PAN) oraz kierowała pracami Zespołu MAB-9 Komitetu „Człowiek i Środowisko” utworzonego przy Prezydium PAN. Była także członkiem innych Komitetów PAN: Komitetu Chemii Analitycznej, Komitetu Inżynierii Środowiska, Komitetu Ochrony Przyrody, Komitetu Nauk Mineralogicznych oraz Komitetu Gleboznawstwa i Chemii Rolnej. Prof. dr hab. Kabata-Pendias była członkiem wielu krajowych i zagranicznych towarzystw naukowych, w tym m.in. Polskiego Towarzystwa Gleboznawczego (w latach 1974-1983 pracowała w Zarządzie Głównym tego Towarzystwa), Polskiego Towarzystwa Mineralogicznego i Polskiego Towarzystwa Geologicznego, International Union of Soil Sciences, Society for Environmental Geochemistry and Health i International Association for Study of Clay. W 1999 roku została powołana na członka prezydium International Society of Trace Element Biochemistry oraz była członkiem New York Academy of Science.

Za działalność naukową Pani Profesor otrzymała wiele odznaczeń państwowych, nagród oraz medali okolicznościowych. Była odznaczona Złotym Krzyżem Zasługi (1979), Krzyżem Kawalerskim Orderu Odrodzenia Polski (1990), Złotą Odznaką PTG (1972) oraz Złotą Odznaką Ministerstwa Środowiska i Gospodarki Wodnej (1995). W 1994 roku została uhonorowana zespołową nagrodą Dyrektora IUNG za prace „, Ocena stopnia zanieczyszczenia gleb i roślin metalami cięzkimi”, a w 1995 roku otrzymała nagrodę zespołową I stopnia przyznaną przez Ministra Rolnictwa i Gospodarki Żywnościowej za osiągnięcie nt. „Rozpoznanie i określenie stopnia zanieczyszczenia pierwiastkami śladowymi środowiska przyrodniczego”. W 1999 roku została uhonorowana Medalem Rektora Akademii Rolniczej w Lublinie, w 2007 roku Medalem Phillipa Duchaufoura, a w 2012 roku Medalem 75-lecia Polskiego Towarzystwa Gleboznawczego.

W okresie II wojny światowej Pani Profesor służyła jako łączniczka w szeregach Armii Krajowej. Z tego tytułu otrzymała Odznakę Żołnierzy AK (1992), Krzyż Armii Krajowej (1994), Krzyż Partyzancki (1995) oraz Odznaką Weteranów Walk o Niepodległość (1996).

Prof. dr hab. Alina Kabata-Pendias wywarła ogromny wpływ na dzisiejsze globalne postrzeganie problemu zanieczyszczenia gleb, jego skutków zdrowotnych i środowiskowych. Do końca swojej działalności naukowej była wierna słowom zapisanym w testamencie naukowym sporządzonym w 1985 roku: ,Dopóki będę aktywna, postaram się przyczynić do lepszego zrozumienia zależności ludzi od geochemicznych właściwości otaczajacego środowiska".

Śmierć prof. dr hab. Aliny Kabaty-Pendias spowodowała, że społeczność naukowa straciła osobę wybitną, wielką profesjonalistkę, którą cechowała odwaga oraz ogromna pracowitość, sumienność i wytrwałość. Pani Profesor była osobą otwartą, koleżeńską i bardzo życzliwą, dlatego dla wielu pracowników naukowych pozostanie wzorem do naśladowania.

\section{PODZIĘKOWANIA}

Autorka składa serdeczne podziękowania paniom: Zofii Frajnt oraz prof. dr hab. Barbarze Maliszewskiej-Kordybach za udostępnienie materiałów archiwalnych związanych z życiem i praca prof. dr hab. Aliny Kabaty-Pendias. W artykule również wykorzystano informacje z Księgi Pamiątkowej IUNG (2000). 